[Tunmer, W., Prochnow, J., \& Chapman, J. (2000). Science Can Inform Educational Practice: The Case of Literacy. New Zealand Annual Review of Education, 9, 133-156]

\section{Science Can Inform Educational Practice: The Case of Literacy ${ }^{1}$}

\author{
WiLliaM TUNMER, JANE PROCHNOW AND JAMES \\ CHAPMAN
}

\section{Abstract:}

Antinaturalists, interpretivists, critical theorists, postmodernists, and deconstructivists have been highly critical of educational research methods that are theory driven, hypothesis testing, or generalization producing. According to extreme versions of these views research can only provide findings that are "contextually bound", in which case educational researchers should concentrate more on "telling stories" than "crunching numbers". With respect to literacy, these critics have questioned the feasibility of attempting to develop a general theory of how children learn to read (and write), and what can be done to maximize the effectiveness of literacy instruction for all children in the light of such findings. Instead, children's literacy experiences are seen as firmly embedded in social contexts that uniquely give meaning to their uses of literacy. In this paper we present an alternative view that begins with a definition of reading literacy that simultaneously incorporates psychological, linguistic, and sociological perspectives. We then present a brief critique of the position that literacy is primarily social, political, and relative, before turning to the primary focus of the paper, which is to provide specific examples of how theory-driven quantitative research can inform educational practice in literacy.

Tn a recent paper Elliot Eisner (1993) argues that the major aim of the enterprise in which we are all engaged is to improve educational practice so that the lives of those who teach and learn are themselves enhanced. "We do research to understand," Eisner suggests, and "we try to understand in order to make our schools better places for both the children and the adults who share their lives there" (p. 10).

We have divided this paper into three parts. First, we argue that the methods of science can be used to improve educational practice in more than minor technical ways. However, we do not espouse

\section{William Tunmer et al.}

methodological monism. Second, we present a definition of reading literacy that simultaneously incorporates psychological, linguistic and sociological perspectives and argue against the view that literacy is primarily social and political. Third, we provide specific examples of how theory-driven, quantitative research can inform educational practice in literacy.

\section{Can Scientific Methodology be Used in Educational Research?}

In a rather tongue in cheek article Gregory Cizek (1995) observes that the quantitative-qualitative debate among educational researchers has not been affirming: "Quantitative researchers are cast as numbercrunching, neo-know-nothing objectivists," whereas "qualitative researchers are scorned as wild-eyed, storytelling mythmakers" (p. 26). Not an attractive choice. However, Cizek admits to being primarily a quantitative methodologist and attributes his allegiance to this tradition to childhood conditioning. When he was little, his mother would often ask him if he was telling the truth or "telling a story."

Interestingly, Eisner (1981, 1983, 1992, 1993), who is often credited with sparking the quantitative-qualitative debate, has consistently argued for a pluralistic rather than a monolithic approach to educational research:

Many methodological voices should be heard. Thus, I certainly do

not reject science ... What I do reject is a view that claims that only scientific methods can inform. (Eisner, 1992, pp. 8-9)

While we agree with Eisner's position, there are those who view quantitative and qualitative a pproaches as fundamentally incompatible, a position referred to as the incompatibility thesis. Because this issue has important implications for educational research, we provide a brief critique of the thesis. The central claim of the thesis is that quantitative and qualitative methodologies reflect underlying epistemological paradigms that are of necessity mutually exclusive and antagonistic (Smith, 1983; Smith \& Heshusius, 1986). The interpretivist paradigm is claimed to support qualitative methods and the positivist paradigm is claimed to support quantitative methods. According to the interpretivist paradigm, the scientific study of the social world is impossible because all human activities, including learning and teaching, involve beliefs, values, intentions, and goals that give the activities meaning. But to understand the meanings assigned to activities requires that the meanings be placed within a social context; that is, interpretations of human actions are contextually bound. Because social contexts uniquely 
give meaning to actions, educational researchers can only provide findings that are bound to particular settings, according to the incompatibility thesis. As Smith (1983) argues, "the essence of understanding is to put oneself in the place of the other - something which is possible if one possesses a degree of empathy with the other or has the disposition to recreate the experiences" (p. 12). This conceptualization gave rise to the view that educational research should focus on "the construction and reconstruction of personal and social stories; learners, teachers, and researchers are storytellers and characters in their own and other's stories" (Connelly \& Clandindin, 1990). As Smith and Heshusius (1986) put it, perhaps educational research "is nothing more or less than another voice in the conversation - one that stands alongside those of parents, teachers, and others" (p. 11).

The incompatibility thesis incorrectly linked objective-quantitative research to positivism, an epistemological position that was rejected decades ago as an accurate portrayal of the scientific method. Positivism defined truth as a correspondence between language and an independently existing reality. The structures of elementary propositions were thought to correspond in some way with the structures of objects in the state of affairs in the world that make the propositions true. The core tenet of positivism was the verifiability principle, the idea that statements are meaningful if and only if they can be verified empirically. The verifiability principle, and positivism more generally, have been thoroughly repudiated.

As Howe and Eisenhart (1990) pointed out,

The picture of empirical science envisioned by positivism, in which observation could be strictly separated from and remain untainted by the purposes that animate the conduct and evaluation of scientific investigation, has been replaced by the notion that all scientific investigation is inherently theory-laden. Consequently, because all scientific investigation is inherently laden with theory, inherently an outgrowth of human purposes and theoretical constructions, it is, broadly speaking, inherently interpretive. (p. 3)

In recent years the incompatibility thesis has fallen on hard times, as there are currently no strong pragmatic or epistemological reasons for viewing quantitative and qualitative approaches as mutually exclusive. Eisner (1993) argued that "the battle that once ensued to secure a place for qualitative research in education has largely been won" (p. 8), and
Peshkin (1993) provided compelling arguments and examples supporting the use of qualitative methods in educational research. Gage (1989) maintained that quantitative and qualitative approaches are not only compatible but often mutually supportive. In principle then, a thoroughgoing integration of qualitative and quantitative methods not only appears to be possible, but highly desirable.

But suppose these arguments are rejected and the interpretivist claim is accepted that educational research can only provide findings that are firmly embedded in social contexts, in which case researchers would be restricted to using qualitative methods like narrative inquiry, or story telling. Where would this leave us? Nowhere, we believe. To paraphrase Cizek (1995, p. 27), if research doesn't relate to anything we currently know (i.e., if it isn't theory driven), if it doesn't address a question of interest posed by the researcher (i.e., if it isn't hypothesis testing), or if it doesn't produce knowledge that others can use because it is bound to a particular setting (i.e., if it isn't generalizable), then how can it even be called research? Even critical theorists who engage in discourse analysis are guided by hypotheses that are generalizable, such as that the ultimate aim of recent government policy in New Zealand was to privatize education. This hypothesis can in turn be placed within a broader socio-economic theory of the distribution of power and wealth in the country. In short, the incompatibility thesis is simply wrong. Educational research is more than just telling stories.

\section{What is Literacy?}

The term literacy is used so broadly now that the term reading literacy will be used to avoid confusion. In our work we have attempted to develop a definition of reading literacy that simultaneously incorporates psychological, linguistic and sociological perspectives. Accordingly, we define reading literacy as the ability to read at a level necessary for selfsustained growth in literacy; to understand in print what would be expected to be understood in the corresponding spoken language by native speakers of the same age; and to understand, use and reflect on written texts, in order to achieve one's goals, to develop one's knowledge and potential, and to participate in society.

From a psychological perspective, reading literacy can be viewed as a continuum of skills that vary between individuals and cultures, and within individuals over time. Regarding the latter, it would not make sense to call a two-year-old child who cannot read illiterate, or to expect 9 -year-old children to demonstrate the same level of reading literacy as 
14-year-old children or adults. Learning to read and "reading to learn" are developmental processes that take place over time. (Tunmer \& Chapman, 1998a; Tunmer \& Hoover, 1992).

A feature common to most psychological theories of reading development is the assumption that children must first achieve a reasonable degree of fluency in reading text before the development of more advanced levels of reading comprehension can occur (e.g., Chall, 1983; Gough \& Hillinger, 1980; Juel, 1991; Pressley, 1998; Spear-Swerling \& Sternberg, 1996). Beginning readers who fail to develop fluency in recognising the words of connected text will encounter difficulty in comprehending and thinking about what they are reading because inefficient lexical access (or retrieval of word meanings from lexical memory) disrupts the temporary representation of text in working memory (Perfetti, 1985). In contrast, rapid and efficient access to the mental lexicon frees up cognitive resources for allocation to comprehension and text integration processes; that is, for self-sustained growth in literacy.

Self-sustained growth in literacy refers to the ability to read to extend one's knowledge. Such children have moved beyond the "learning to read" phase of reading development and are spending increasing amounts of time "reading tolearn," where reading has become a tool for exploring subject matter areas and for dealing with daily affairs (Calfee \& Drum, 1986). At this stage of development children are concentrating more on using strategies to aid reading comprehension, not word recognition. The use of strategies to monitor ongoing comprehension processes includes evaluating the content of text critically for internal consistency and compatibility with prior knowledge, and checking to see if comprehension is occurring by engaging in such activities as periodic review and self-questioning (Baker \& Brown, 1984). When a breakdown in comprehension occurs, strategic readers employ the "fixup" strategies necessary to improve their understanding of text, such as rereading a passage to see if it is more understandable the second time around or reading ahead to see if an apparent ambiguity or inconsistency may be resolved later in the text. Strategic readers extend their understanding of text beyond literal comprehension by drawing and testing inferences of many kinds, including interpretations, predictions, and conclusions. Cross-cultural studies of reading suggest that there is a common core of psychological processes that are required for developing self-sustained literacy, including the coordination of eye movements into fixations and saccades, the development of metalinguistic abilities, the development of speed and automaticity in the identification of word units, and the utilization of sentence-level and text integration processes to construct meaning from text (Foorman \& Siegel, 1986; Leong \& Joshi, 1997).

The second part of the definition refers to the intimate connection between reading and language. At the simplest level, reading literacy may be defined as the ability to obtain meaning from print. However, the major shortcoming of this definition is that no reference is made to the language being read. As Gough (1975) argued, "knowledge of the language being read is at the heart of the reading process, and without that knowledge reading could simply not take place" (p. 15). Comprehending text requires the full set of linguistic skills needed to comprehend spoken language, skills such as determining the intended meaning of individual words, assigning appropriate syntactic structures to sentences, deriving meaning from individually structured sentences, and building meaningful discourse on the basis of sentential meaning (Hoover \& Tunmer, 1993).

From this perspective reading can be viewed as the translation from print to a form of code from which the reader can already derive meaning (i.e. the reader's spoken language). Children who have successfully learned to read should minimally be able to understand in print anything that they can understand in their spoken language. However, the task of learning how to map the printed text onto one's existing language may be particularly problematic for children whose dialect or first language is different from the language of text. Oral language proficiency in non-native speaking children can vary along a continuum from non-speakers who are either hearing the language of instruction for the first time or can only produce a few one-word utterances, to totally fluent speakers whose speech sounds like that of native speakers of the same age. In between are children who are fairly easily understood and whose speech contains complete sentences, but with systematic errors in syntax and deficiencies in lexical knowledge. In comprehending spoken language these children also exhibit subtle deficiencies in discourse integration processes. These are processes that involve the application of pragmatic and inferential rules to combine new information (i.e., propositions) with old information (i.e., prior knowledge, knowledge of the preceding discourse, and knowledge of the situational context) to form larger sets of interrelated propositions.

Deficiencies in the different components of spoken language functioning would be expected to impede the development of the 
ability to comprehend text (Tunmer, 1989; Tunmer \& Hoover, 1993). Students with poorly developed vocabulary knowledge should have greater difficulty in comprehending words after they have been recognized. Students who are deficient in syntactic knowledge should have greater difficulty in understanding written sentences and in using sentence context as an aid to word identification. Students who have problems in relating the meaning of each new sentence in spoken discourse to the meanings of the sentences that preceded it (i.e., discourse integration processes) should have greater difficulty in comprehending and recalling stories and passages.

Reading literacy, however, is more than comprehending text. According to the third part of the definition, the level of literacy required varies according to cultural demands and involves procedural knowledge, the ability to do something. In this view reading literacy is a fundamental enabling skill, a tool by which readers acquire the knowledge necessary for participating fully in the processes of society (social, cultural, and political) and for achieving their personal goals and developing their potential. For literate school-age readers this means being able to adjust their orientation to a given text to fit the purpose for which they are reading (e.g., entertainment, scanning text for a specific piece of information, increasing knowledge in a particular area, or obtaining information to accomplish a task or solve a problem). As a socially defined concept, reading literacy represents an aspiration rather than a reality, as not all individuals will achieve the level of reading literacy needed to function effectively in an information oriented, "high tech" world. Advanced levels of literacy require higher-level processing skills such as problem solving and critical thinking.

While the definition of reading literacy that we have proposed includes psychological, linguistic, and sociological perspectives, some argue that reading is, in essence, a socially constructed phenomenon (Street, 1993). Literacy experiences are seen as firmly embedded in social contexts that uniquely give meaning to the uses of literacy. However, viewing reading as a social act is almost certainly incorrect, as reading is surely one of the least social of human activities. That's why libraries are quiet places. Interacting with others while reading only disrupts reading. In response to the claim that readers cannot be separated from the society that gives meaning to their uses of literacy, Gough (1995) asks, why not?

When I watch a Wimbledon tennis match, I separate those players from the society which gives meaning to their uses of their racquets;
I am interested in the players and their game, not that society. Why can't I do the same with readers?

According to this view, then, literacy is an autonomous set of cognitive and linguistic skills that enable individuals in different cultures to do different things in response to cultural demands. If literacy is defined solely in terms of its uses in social contexts, then there would be as many definitions of literacy as there are social groups.

Those who maintain that literacy is socially embedded also claim that literacy is largely a political matter. Although it is certainly true that literacy is often an intensely political issue in many societies, advocates of what is called critical literacy want to make the teaching of literacy political. Critical literacy refers to literacy practices that promote political change. As Colin Lankshear (1997) puts it, critical literacy "engages students and teachers together in making explicit the socially constituted character of knowledge, and asking in whose interests particular 'knowledges' are thus constituted, legitimated, and perpetuated" (pp. 43-44). In a recently published book by the Primary English Teaching Association in Australia entitled Critical literacies in the primary classroom (Knobel \& Healy, 1998), it is stated that "teachers who subscribe to critical literacy have a stake in social change ... and aim to encourage their students to investigate, question and even challenge relationships between language and social practices that advantage particular social groups over others" (p. 2).

We disagree with the suggestion that literacy instruction should be the vehicle for bringing about social change. Instead, we think educators should do their best to keep politics out of literacy instruction. Literacy has to do with being able to gain meaning from printed materials on topics the reader chooses to find out about, and being able to put in writing ideas that the writer wishes to convey to others or reflect on. These abilities, which are more than simply a set of "technical skills," can be empowering: the literate person can read to learn and write to influence. But being a literate person does not mean having a particular political view, for example, that the major purpose of the education system is cultural reproduction. Such a claim may in fact be correct but holding it has nothing to do with being literate, in our view.

Citizens in a democratic society disagree about many things abortion, gay rights, welfare, taxation, economic policy, social policy, treaty obligations, becoming a republic, genetic engineering, nuclear energy, employment contracts, and so on. But regardless of our political differences, we all want out children to learn to read and write. And 
most of us want our children to make up their own minds about political issues. As Gough (1995) has argued:

Some of us might like our children (and those of others) inculcated with our own views. But what if their teachers hold views with which we disagree? Do we really want our children's political views

shaped by the views of their teachers? (p. 82)

In summary, we do not believe that literacy should be defined in terms of one's political views. Being literate does not mean being politically aware or being able to use printed language in an emancipatory way. Whether a person learns to read and write Chinese by studying the writings of Mao or the teachings of Confucius, he or she is still literate in Chinese without necessarily accepting the views of either Mao or Confucius.

\section{Can Science Inform Educational Practice in Literacy?}

In support of our claim that science can inform educational practice in literacy, we provide examples of research carried out by a group of us at Massey University. We also argue that our research constitutes more than a "technocratic" effort to improve the fine details of literacy instruction. The whole language versus code emphasis debate has generated an enormous amount of controversy in education systems throughout the world, and has certainly polarized the reading community (Tunmer \& Chapman, 1996). In one form or another the debate over reading methods has raged for more than a century, with the pendulum swinging back and forth between approaches that emphasize the development of word-level strategies, or phonic skills, and those that don't. One would think that after all this time the teachers themselves would have discovered the most effective approach to teaching literacy by trial and error, leaving the academics to figure out why the approach is best. There is, however, an explanation for why the debate has gone on for so long, and it comes from linguistic science. But more on that later.

There are four defining features of the whole language approach to literacy instruction: the use of a literature-based approach, an emphasis on child-centered instruction, the integration of reading and writing, and an emphasis on meaning construction (Tunmer \& Chapman, 1999). Of these, it is the latter characteristic that has been the source of so much controversy. This may initially seem somewhat surprising, given that the goal of any literacy program must be to help children derive meaning from print and express meaning in print. The question, however, is how best to do it.

A key assumption of the whole language philosophy is that learning to read is essentially like learning to speak; both abilities are thought to develop "naturally". From this assumption whole language theorists concluded that reading instruction should be modeled on first-language acquisition, where the focus is on meaning construction, not the abstract structural units by which meaning is conveyed. It therefore followed that language should be kept "whole" during instruction. Kenneth Goodman (1986), a leading proponent of the whole-language view of literacy acquisition, argued that teachers make learning to read difficult "by breaking whole (natural) language into bitesize abstract little pieces" (p. 7), and that this postpones the natural purpose of language, which is the communication of meaning. If children are immersed in a printrich environment in which the focus is on the meaning of print, they will readily acquire reading skills, according to this view. As John Smith and Warwick Elley (1994), two leading proponents of whole language in New Zealand, put it, "children learn to read themselves; direct teaching plays only a minor role" (p. 87).

Proponents of whole language further claim that reading is a process in which minimal word-level information is used to confirm language predictions. Readers are thought to use the syntactic and semantic redundancies of language to generate hypotheses, or guesses, about the text yet to be encountered, and to play little attention to the majority of the words of text because language follows a predictable pattern. Instead, they use the fewest cues possible to make a prediction and test their guess against their developing meaning. As Smith and Elley (1994) argue, children "learn to read with minimal input from the text, predicting and confirming and making sense as they go" (p. 142). Children in whole language programs are therefore urged to use sentence context as the primary strategy for recognizing words in text. They are taught to monitor for meaningfulness and to make corrections only when necessary to make sense. When children encounter a difficult word, they are encouraged to guess what the word might be, or, if necessary, to skip the word and read to end of the sentence, and then reread the sentence and put in a word that makes sense. Children often receive praise if the response fits the context, even if the response is incorrect.

Children in whole language programs are also taught to use lettersound cues, but only very sparingly and mainly to confirm language 
predictions. English orthography is thought to contain so many irregularities that focusing too much attention on teaching letter-sound patterns will not only waste valuable time but possible even confuse children and impede progress. Brian Cambourne (1988), the leading proponent of whole language in Australia, explicitly states that if all else fails, beginning readers might try to work out the sounds of the first couple of letters in an unfamiliar word, but only as a last resort.

This approach to reading instruction has been actively promoted by the Ministry of Education in New Zealand. In the Ministry's most recent publication on reading instruction, The Learner as Reader (1996), it is explicitly stated that the first strategy children should be encouraged to use when confronted with an unfamiliar word is to "try reading from the beginning of the sentence again and think what would fit" (p. 50). In the introduction to the Ready to Read Series used in New Zealand schools, reading is described as "a constantly repeated process of sampling, predicting, checking, confirming, and self-correcting" (Reading and Beyond, 1997, p. 7). Readers "predict or anticipate the meaning of unknown text ... [and] check these predictions against what they have read and what they know of the world, and either confirm or self-correct predictions by rereading, reading on, or referring to other cues" (p. 7).

The theoretical model of reading upon which the whole language approach to literacy is based has generally been rejected by the scientific community. Michael Pressley (1998), the current editor of the Journal of Educational Psychology, recently stated that "the scientific evidence is simply overwhelming that letter-sound cues are more important in recognizing words than either semantic or syntactic cues ..." (p. 16), and that heavy reliance on the latter is a "disastrous strategy" for beginning readers (p. 32). Our view is that predicting words from context is a highly ineffective and inappropriate learning strategy, and that encouraging children to rely primarily on context to identify unfamiliar words counteracts many of the good things that teachers do. Instead, children should be encouraged to look for familiar spelling patterns first and to use context to confirm hypotheses about what unfamiliar words might be, based on available word-level information.

There are three immediate difficulties with the theoretical underpinnings of whole language. First, if it is indeed true that children "learn to read themselves" with only a limited amount of direct instruction being required (because they need only use the same underlying strategies and mental capacities that enabled them to acquire spoken language), then why do a staggering 20 to 25 percent of all 6-year-old children in New Zealand require expensive, intensive, one-to-one Reading Recovery tutoring after having been immersed in a print-rich environment for an entire year? Most of these children have made little or no progress toward gaining independence in reading during their first year of schooling. The answer is straightforward. Learning to read is not "natural." Written language is a culturally transmitted artifact whereas spoken language is part of the biological heritage of the human species. As Perfetti (1991) pointed out:

Learning to read is not like acquiring one's native language, no matter how much someone wishes it were so. Natural language is acquired quickly with a large biological contribution. Its forms are reinvented by every child exposed to a speech community in the first years of life. It is universal among human communities. By contrast literacy is a cultural invention. It is far from universal. And its biological contribution to the process has already been accounted for, once it is acknowledged that it depends on language rather than parallels it. (p. 75).

The second difficulty concerns the claim by whole language theorists that language follows a predictable pattern. Linguists would strongly disagree. One of Noam Chomsky's (1965) greatest insights into the nature of human language was that virtually every sentence we produce or comprehend is novel, never having appeared before in the history of the universe. For example, the sentence you are presently reading is one that you have never seen in your life, but you understand it perfectly well. Because natural human languages are discrete combinatorial systems with the mathematical property of recursion, the number of sentences that a speaker can potentially understand or produce is without limit. At first glance, the structural representations of sentences all look pretty much the same. However, they are a bit like snowflakes. When you look more closely, they are all very different, even though they are generated by the same finite set of phrase-structure rules. The key point is this. The sentences of English, and all other natural languages, do not follow a predictable pattern because the words of sentences are organized hierarchically, not linearly. Contrary to what behaviourists like Skinner thought, each word of a sentence does not serve as the stimulus to the word that immediately follows it.

The third major difficulty with the theoretical underpinnings of whole language is the assumption that the words of text are highly 
predictable as a consequence of the developing meaning of text. Research has repeatedly demonstrated that the words that can be predicted in text are typically frequently occurring function words that children can already recognize rather than less frequently occurring but more meaningful content words (Gough, 1983). The average predictability of content words (nouns, verbs, adjectives) in running text is less than 10 percent, compared to about 40 percent for function words (e.g., on, the, to). To illustrate this point, Adams (1991) compared the following frequent and infrequent words of a passage from a typical school text:

$\begin{array}{cc}\text { Frequent Words } & \text { Infrequent Words } \\ \text { when } & \text { infection } \\ \text { you } & \text { doctor } \\ \text { an } & \text { penicillin } \\ \text { to } & \text { medicine } \\ \text { the } & \text { discovered } \\ \text { and } & \text { Alexander Fleming } \\ \text { he } & \text { melon } \\ \text { some } & \text { mold } \\ \text { that } & \text { poison } \\ \text { by } & \text { bacteria } \\ & \text { antibiotics } \\ & \text { protect } \\ & \text { germs } \\ & \text { disease }\end{array}$

She then asked, "Given a passage constructed of these words, how good would your comprehension be if you read only the frequent while ignoring the infrequent?" (p. 49). Because the information conveyed by words varies inversely with their frequency, the teaching approach recommended by whole language advocates presents us with the following dilemma: While children are taught to rely on the meaning of the passage to infer the meanings of its less familiar words, the meaning of the passage depends disproportionately on the meanings of its least familiar and least predictable words. For those readers who still believe that context plays a major role in identifying the words of text, try to predict the upcoming words of the following sentence (cover the words first and expose them one at a time): Common ... sense ... suggests ... that ... prior ... context ... provides ... little ... if ... any ... help $\ldots$ in $\ldots$ predicting $\ldots$ each $\ldots$ successive ... word ... in ... a ... sentence $\ldots$ like $\ldots$ the $\ldots$ one $\ldots$ just ... read.
But, some may object, the vast majority of children in whole language programs do in fact learn to read through an instructional approach that places primary emphasis on the use of language prediction skills to identify words in text. At this point we must avoid a common source of misunderstanding by recognizing that most children - probably 75 percent - will independently discover the enormous value of learning to read in an alphabetic orthography regardless of the method of instruction to which they are exposed. Knowledge of spelling-to-sound patterns provides a highly efficient mechanism for acquiring word-specific knowledge, including knowledge of irregularly spelled words (Ehri, 1992). Making use of systematic mappings between subcomponents of written and spoken words enables beginning readers to identify unfamiliar words which in turn, results in the formation of sublexical connections between orthographic and phonological representations in lexical memory. These amalgamated representations provide the basis for rapid and efficient access to the mental lexicon, which frees up cognitive resources for allocation to comprehension and text integration processes.

There is little interaction between orthographic and phonological codes in the word processing of those beginning readers who rely mostly on partial visual cues and contextual guessing at the expense of phonological information. The word recognition skills of these children remain relatively weak because they do not develop as rich a network of sublexical connections between orthographic and phonological representations in lexical memory as normally developing readers. Consequently, these children experience progressive deterioration in rate of reading development as they grow older. As Adams and Bruck (1993) pointed out, "without the mnemonic support of the spelling-tosound connections, the visual system must eventually become overwhelmed: the situation in which [these children] are left is roughly analogous to learning 50,000 telephone numbers to the point of perfect recall and instant recognition" (p. 130).

Returning to our earlier point, is there any evidence supporting the claim that most children exposed to an alphabetic orthography will rely primarily on word-level information to identify unfamiliar words in text, even though they may have been told to do otherwise? To answer this question we carried out the following extremely simple study as part of a longitudinal research project in which the literacy development of 152 children in 22 schools was closely tracked from school entry to the middle of Year 3 (Tunmer, Chapman, Ryan \& 
Prochnow, 1998). We simply asked each child the following question, once in Year 1 and again in Year 2: "When you are reading on your own and come across a word that you don't know, what do you do to try to figure out what the word is?" The children's responses were coded according to whether any reference was made to the use of word-level information, no reference was made to the use of word-level information, or no response was given. Examples of word-level responses included "sound it out," "hear all the letters," "think of the sounds," "listen to what the letters are" "look at the beginning, middle and end, then I try to work it out." Examples of nonword level responses included "guess," "think, guess what the word is," "read it all over again," "I leave it," "miss it and go to the end and go back and guess a word that makes sense," "have a look at the picture," "read on," "put my finger on the book and try the other words and get a word that makes sense."

The results showed that at each year level the majority of children indicated that they used word-level information to identify unfamiliar words in text, a tendency that increased as the children grew older, from 52 percent in Year 1 to 66 percent in Year 2. Although these results are important, the more interesting question is whether there is a relationship between what children say they do to identify unfamiliar words when they are in Year 1, and their reading achievement in Years 2 and 3 . The results were very clear-cut. On all reading and readingrelated measures there were highly significant differences between the groups that consistently favoured the children who used word-level information to identify unfamiliar words. We also examined the relationship between Year 1 response category and placement in the Reading Recovery program. Children who were placed in Reading Recovery after a year of reading instruction were over $4 \frac{1}{2} 2$ times more likely to have indicated in their first year of schooling that they preferred using nonword-level strategies such as contextual guessing and picture cues, than word-level strategies when confronted with an unfamiliar word in text.

In response to the claim by whole language proponents that English orthography is too irregular to be of much use, it can be argued that because no word in English is completely phonologically opaque, even irregularly spelled words such as stomach, castle, and spinach provide accurate phonological cues to the word's identity. When beginning readers apply their developing knowledge of spelling-to-sound patterns to unfamiliar irregular words, the result will often be close enough to the correct phonological form that sentence context cues can be used to arrive at a correct identification. In support of this suggestion we found that children in Years 2 and 3 achieved an average score of 76 percent when asked to correct the regularized pronunciations of 80 irregular words that were orally presented in underdetermining sentence contexts; e.g." "The football hit him in the stow-match," "The children used the blocks to build a kastol" "My brother likes to eat spy-nach" (Tunmer \& Chapman, 1998b).

Further support for this claim comes from the results of another study we carried out that included measures of word recognition ability, language prediction skill, letter-sound knowledge, and contextual facilitation. In the latter task beginning readers were asked to read aloud 80 irregularly spelled words, first in isolation and then, in another test session, in underdetermining sentence contexts (e.g. "He couldn't find his money"). Children's ability to read in context words that they were unable to read in isolation was calculated as the ratio of contextual gain to potential improvement, as indicated by the number of words presented in isolation that were not correctly identified. Contingency analyses of the data indicated that not only is letter-sound knowledge necessary for acquiring word-specific knowledge (as measured by the ability to read irregular words), but it is also necessary for taking advantage of the constraints of sentence context in identifying unfamiliar irregular words. Only children who had begun to acquire letter-sound knowledge were able to benefit from context. The data further indicated that the good decoders (children who demonstrated a high level of letter-sound knowledge) did not need to rely on context as often because of their superior ability to recognize words in isolation, but when they did rely on context, they were much more likely to identify unfamiliar words than less skilled decoders. A multiple regression analysis of the data revealed that letter-sound knowledge also made a much greater contribution to the identification of unfamiliar exception words primed by context than did language prediction skill. That is, even in the extreme case of learning to recognise irregularly spelled words, knowledge of spelling-to-sound patterns is much more important than the ability to use the constraints of sentence context. These findings directly contradict the fundamental theoretical assumptions of whole language, and suggest that context should only be used to supplement word-level information, not to substitute for it. 
To discover mappings between spelling patterns and sound patterns, children must be able to segment spoken words into subcomponents, an ability referred to as phonological awareness (Tunmer \& Rohl, 1991). Given the evidence indicating that the ability to use letter-sound relationships is much more important than the ability to use the constraints of sentence context, the development of phonological awareness is especially important. However, many beginning readers find it extraordinarily difficult to detect phonological sequences in spoken words, even though they are clearly capable of discriminating between speech sounds and using phonemic contrasts to signal meaning differences. The important distinction is that using a phonemic contrast to signal a meaning difference (e.g., "pig" vs "big"), which is done intuitively and at a subconscious level, is not the same as the metalinguistic act of consciously reflecting on and manipulating the phonemic elements of speech. Examples of the latter include using counters to represent each phoneme in a word like "bat", and blending separate sounds together, such as "buh ah tuh", to form a word.

Consciously reflecting on phonemic segments is much more difficult for children because there is no simple physical basis for recognizing phonemes in speech. In the late 1960s linguists made the important discovery that it is not possible to segment a speech signal such that each segment corresponds to one and only one phoneme (Liberman, Cooper, Shankweiler \& Studdert-Kennedy, 1967). Rather, the information necessary for identifying a particular phoneme overlaps with that of another phoneme, a phenomenon referred to as parallel transmission of phonemic content. Because phonemic segments do not exist in the acoustic signal per se but must be constructed from it, children must develop an awareness of an entity that is inherently abstract. They must gain access to the products of the mental mechanism responsible for converting the speech signal into a sequence of phonemes.

These considerations explain why many children who have begun formal reading instruction fail to benefit from either letter-name knowledge or letter-sound knowledge in learning to recognize words, and why phonic-based approaches have repeatedly been abandoned over the years in an attempt to find alternative approaches with lower rates of reading failure. Because there is no one-to-one correspondence between phonemes and segments of the acoustic signal, it is not possible to pronounce in isolation the sound corresponding to most phonemes. Consequently, the strategy of simply "sounding out" a word like bag will result in "buh ah guh", a nonsense word comprising three syllables. Letter sounds and letter names are only imprecise physical analogues of the phonemes in spoken words. Whether children learn to associate the sound "buh" or the name "bee" or both with the letter $b$, they must still be able to segment the sound or name to make the connection between the letter $b$ and the abstract phoneme $/ \mathrm{b} /$, which cannot be pronounced in isolation. In short, beginning readers must become phonologically aware.

In support of these claims are studies showing that children's level of phonological awareness before they begin formal reading instruction predicts their later reading achievement better than any other measure. In Australia, Share, Jorm, Maclean and Matthews (1984) found that of 39 measures taken at school entry, phonological awareness was the strongest predictor of reading achievement after two years of reading instruction. In our longitudinal study in New Zealand (Tunmer, Chapman, Ryan, \& Prochnow, 1998) we found that of all our school entry variables, phonological awareness was the best predictor of reading comprehension performance in Year 3. The magnitude of the predictive correlation was almost identical to that reported in the Australian study: 0.61 as against 0.62 .

We also found in our longitudinal study that the children identified as having reading problems were, without exception, experiencing difficulties in detecting phonological sequences in spoken words and relating them to letters in printed words. Results indicated that children who were independently selected by their schools for Reading Recovery showed major deficiencies in phonological processing skills during the year preceding entry into the program; that participation in Reading Recovery did not eliminate these deficiencies; and that the failure to do so severely limited the immediate and long-term effectiveness of Reading Recovery (Chapman, Tunmer, \& Prochnow, in press). The major shortcoming of Reading Recovery is that it stresses the importance of using information from many sources in identifying unfamiliar words in text without recognizing that skills and strategies involving phonological information are of primary importance in beginning literacy development. In support of this claim Iversen and Tunmer (1993) reported that the effectiveness of Reading Recovery could be improved considerably by incorporating more intensive and explicit training in phonological processing skills into the program. Greaney, Tunmer, and Chapman, (1997) found that even the most severely disabled readers, most of whom had been referred on from 
Reading Recovery, were able to derive long-term benefits from explicit instruction in phonological processing skills.

Finally, several studies have reported that training in phonological awareness during or before reading instruction produces significant experimental group advantages in reading achievement, especially when combined with letter-sound training (Lundberg 1994; Tunmer \& Rohl, 1991). In our own work we found that exposing new entrants to supplementary materials and procedures designed to facilitate the development of phonological processing skills and strategies resulted in significant gains in reading achievement over a matched comparison group by the end of the first year (Tunmer, Chapman, Ryan \& Prochnow, 1998). By the end of the second year the gains were not only maintained but had increased to an average difference in reading age of 14 months. The materials we used included the thoroughly researched Sound Foundations program developed in Australia by Brian Byrne and Ruth Fielding-Barnsley (1991). We wish to emphasis that the overall program that we implemented did not follow a rigid, skill-and-drill approach to literacy instruction in which word-level skills are largely taught in isolation with little or no emphasis placed on developing within beginning readers an understanding of how and when to apply such knowledge. Rather, our approach was based on the assumption that beginning readers must become active problem solvers with regard to graphic information (Tunmer \& Chapman, 1999). Emphasis was therefore placed on developing within children selfimproving, metacognitive strategies for acquiring spelling-sound relationships.

\section{Concluding Remarks}

We would like to conclude our paper by calling for an end to the paradigm wars that have plagued educational research. As Ned Gage (1989) pointed out, the competing paradigms are largely a reflection of the interdisciplinary nature of educational research:

It was psychology, in large part, that bred the objective-quantitative approach to research ... It was anthropology, in large part, that spawned the interpretive-qualitative approach. It was mainly the work of analysts from economics, political science, and sociology that produced critical theory.

Gage argues, and we agree, that all three approaches have made important contributions to educational research.
With respect to literacy research, some interpretivists and critical theorists might be inclined to dismiss our work as yet another example of technocratic fine-tuning that fails to consider the larger picture; namely, that what is more urgently needed is a reconsideration of the whole structure of society in which literacy instruction takes place. We agree that the latter is very important, but we ask our critics to consider this. Our data indicate that the whole language view of literacy development, which proposes that children essentially "learn to read by themselves" when immersed in a print-rich environment, may be particularly disadvantageous to certain groups within our society; that is, whole language may be one of the most powerful mechanisms by which cultural reproduction is achieved by schools. We know that prior to school entry, exposure to certain kinds of activities in the home greatly facilitates the development of preliterate phonological awareness. These activities include looking at books and playing games that increase knowledge of letter names and their relation to sounds in words (e.g., "S is for snake"), playing rhyming and sound analysis games and being read books that increase phonological sensitivity (e.g., pig Latin, I spy, nursery rhymes, Dr Seuss books), and manipulating movable letters to form preconventional spellings of words (e.g., FRE for fairy). In what kinds of homes are these activities most likely to occur? And would exposure to such activities be particularly beneficial to children entering literacy programs that are based on the assumption that phonological information is of limited importance, or possibly even a hindrance to learning? Keep in mind that phonological awareness at school entry is the best single predictor of future reading achievement. Perhaps the critical theorists and scientists are not as far apart as they think.

Note

1. This article is a slightly modified version of the 1999 Herbison Lecture presented at the Joint Conference of the New Zealand Association for Research in Education and the Australian Association for Research in Education, Melbourne, Australia, December 1999.

\section{References}

Adams, M. J. (1991). Why not phonics and whole language? In W. Ellis (Ed.), All language and the creation of literacy (pp. 40-53). Baltimore, MD: Orton Society.

Adams, M. J., \& Bruck, M. (1993). Word recognition: The interface of educational policies and scientific research. Reading and Writing: An 
Interdisciplinary Journal, 5, 113-139.

Baker, L., \& Brown, A. L. (1984). Metacognitive skills and reading. In P. D. Pearson, R. Barr, M. Kamil, \& P. Mosenthal (Eds.), Handbook of Reading Research (pp. 353-393). New York: Longman.

Byrne, B., \& Fielding-Barnsley, R. (1991). Sound foundations: An introduction to pre-reading skills. Sydney: Peter Leyden Educational.

Calfee, R., \& Drum, P. (1986). Research on teaching reading. In M. C. Whittock (Ed.) Handbook of Research on Teaching (pp. 804-849). New York: MacMillan.

Cambourne, B. (1988). The whole story: Natural learning and the acquisition of literacy in the classroom. Auckland: Ashton Scholastic.

Chall, J. C. (1983). Stages of reading development. New York: McGraw-Hill.

Chapman, J. W., Tunmer, W. E., \& Prochnow, J. E. (in press). Does success in the Reading Recovery program depend on developing proficiency in phonological processing skills? A longitudinal study in a whole language instructional context. Scientific Studies in Reading.

Chomsky, N. (1965). Aspects of the theory of syntax. Cambridge, MA: MIT Press.

Cizek, G. (1995) Crunchy granola and the hegemony of the narrative. Educational Researcher, 24, 26-28.

Connelly, F. \& Clandinin, D. (1990). Stories of experience and narrative inquiry. Educational Researcher, 19, 2-14.

Ehri, L. C. (1992). Reconceptualizing the development of sight word reading and its relationship to recoding. In P. B. Gough, L. C. Ehri, \& R. Treiman (Eds.), Reading Acquisition (pp. 107-143). Hillsdale, NJ: Erlbaum.

Eisner, E. W. (1981). On the differences between scientific and artistic approaches to qualitative research. Educational Researcher, 10, 5-9.

Eisner, E. W. (1983). Anastasia might still be alive, but the monarchy is dead. Educational Researcher, 12, 13-14, 23-24.

Eisner, E. W. (1992). Are all causal claims positivistic? A reply to Francis Schrag. Educational Researcher, 21, 8-9.

Eisner, E. W. (1993). Forms of understanding and the future of educational research. Educational Researcher, 22, 5-11.

Foorman, B. R. \& Siegel, A. W. (Eds.) (1986). Acquisition of reading skills: Cultural constraints and cognitive universals. Hillsdale, NJ: Erlbaum.

Gage, N. L. (1989). The paradigm wars and their aftermath: A "historical" sketch of research on teaching since 1989. Educational Researcher, 18, 4-10.
Goodman, K. S. (1986). What's whole in whole language: A parent-teacher guide. Portsmouth, NH: Heinemann.

Gough, P. B. (1975). The structure of language. In D. Duane \& M. Rawson (Eds.), Reading Perception and Language. Baltimore, MD: York Press.

Gough, P. B. (1983). Context, form and interaction. In K. Rayner (Ed.), Eye Movements in Reading: Perceptual and Language Processes. (pp. 203-211). San Diego, CA: Academic Press.

Gough, P. B. (1995). The new literacy: Caveat emptor. Journal of Research in Reading, 18, 79-86.

Gough, P. B., \& Hillinger, M. L. (1980). Learning to read: An unnatural act. Bulletin of the Orton Society, 30, 176-196.

Greaney, K., Tunmer, W., \& Chapman, J. (1997). The effects of rimebased orthographic analogy training on the word recognition skills of children with reading disability. Journal of Educational Psychology, $89,645-651$.

Hoover, W. A. \& Tunmer, W. E. (1993). The components of reading. In G. B. Thompson, W. E. Tunmer, \& T. Nicholson (Eds), Reading Acquistion Processes (pp. 1-19). Clevedon, England: Multilingual Matters.

Howe, K., \& Eisenhart, M. (1990). Standards for qualitative (and quantitative) research: A prolegomenon. Educational Researcher, 19, 2-9.

Iversen, A. \& Tunmer, W. (1993). Phonological processing skills and the Reading Recovery program. Journal of Educational Psychology, 85, 112-126.

Juel, C. (1991). Beginning reading. In R. Barr, M. Kamil, P. Mosenthal, \& P. D. Pearson (Eds.), Handbook of Reading Research Volume II (pp. 759-788). New York: Longman

Knobel, M., \& Healy, A. (Eds.) (1998). Critical literacies in the primary classroom. Newtown, New South Wales: Primary English Teaching Association.

Lankshear, C. (1997). Changing literacies. Buckingham: Open University Press.

Leong, C. K. \& Joshi, M. R. (Eds.) (1997). Cross-language studies of learning to read and spell. Dordrecht, the Netherlands: Kluwer Academic Publishers.

Liberman, A. M., Cooper, F. S., Shankweiler, D. P., \& StuddertKennedy, M. (1967). Perception of the speech code. Psychological Review, 74, 431-461. 
Lundberg, I. (1994). Reading difficulties can be predicted and prevented: A Scandinavian perspective on phonological awareness and reading. In C. Hulme \& M. Snowling(Eds.), Reading development and dyslexia (pp. 180-199). London: Whurr.

Ministry of Education. (1996). The learner as reader. Wellington, New Zealand: Ministry of Education.

Ministry of Education. (1997). Reading and beyond. Wellington, New Zealand: Ministry of Education.

Perfetti, C. A. (1985). Reading ability. New York: Oxford University Press.

Perfetti, C.A. (1991). The psychology, pedagogy, and politics of reading. Psychological Science, 2, 70-76.

Peshkin, A. (1993). The goodness of qualitative research. Educational Researcher, 22, 23-29.

Pressley, M. (1998). Reading instruction that works: The case for balanced teaching. New York: Guilford Press.

Share, D. L., Jorm, A. F., Maclean, R., \& Matthews, R. (1984). Sources of individual differences in reading acquisition. Journal of Educational Psychology, 76, 1309-1324.

Smith, J. K. (1983). Quantitive versus qualitative research: An attempt to clarify the issue. Educational Researcher, 12, 6-13.

Smith, J. K. \& Heshusius, L. (1986). Closing down the conversation: The end of the quantitative-qualitative debate among educational researchers. Educational Researcher, 15, 4-12.

Smith, J. W. A., \& Elley, W. B. (1994). Learning to read in New Zealand. Auckland, New Zealand: Longman Paul.

Spear-Swerling, L., \& Sternberg, R. J. (1996). Off track: When poor readers become "learning disabled". Denver, CO: Westview Press.

Street, B. V. (1993). The new literacy studies: Guest editorial. Journal of Research in Reading, 16, 81-97.

Tunmer, W. (1989). The role of language-related factors in reading disability. In D. Shankweiler \& I. Liberman (Eds.), Phonology and reading disability: Solving the reading puzzle (pp. 91-131). Ann Arbor, MI: University of Michigan Press.

Tunmer, W. \& Chapman J. (1996). Whole language or whole nonsense? New Zealand Journal of Educational Studies, 31, 77-84.

Tunmer, W., Chapman, J. (1998a). Implicit and explicit processes in reading acquisition. In K. Kirsner, C. Speelman, A. O’Brien-Malone, M. Anderson \& C. Macleod (Eds.), Implicit and explicit mental processes (pp. 357-370). Mahwah, NJ: Lawrence Erlbaum Associates.
Tunmer, W., Chapman, J. (1998b). Language prediction skill, phonological recoding ability, and beginning reading. In C. Hulme \& R.M. Joshi (Eds.), Reading and spelling: Development and disorder (pp. 33-67). Hillsdale, NJ: Lawrence Erlbaum Associates.

Tunmer, W. \& Chapman, J. (1999). Teaching strategies for word identification. In G. B. Thompson \& T. Nicholson (Eds.), Learning to read: Beyond phonics and whole language (pp. 74-102). New York: Teachers College Press.

Tunmer, W. E. \& Hoover, W. (1992). Cognitive and linguistics factors in learning to read. In P. Gough, L. Ehri \& R. Treiman (Eds.), Reading Acquisition (pp.175-214). Hillsdale, NJ: Erlbaum.

Tunmer, W. \& Hoover, W. (1993). Components of variance models of language-related factors in reading disability: A conceptual overview. In M. Joshi \& C.K. Leong (Eds.), Reading disabilities: Diagnosis and component processes (pp. 135-173). Dordrecht, The Netherlands: Kluwer Academic Publishers.

Tunmer, W., Chapman, J., Ryan, H., Prochnow, J. (1998). The importance of providing beginning readers with explicit training in phonological processing skills. Australian Journal of Learning Disabilities, 3, 4-14.

Tunmer, W. \& Rohl, M. (1991). Phonological awareness and reading acquisition. In D. Sawyer \& B. Fox (Eds.), Phonological awareness in reading: The evolution of current perspectives, (pp. 1-30). New York: Springer-Verlag.

\section{The authors}

All the authors are from the Department of Learning and Teaching, Massey University, Palmerston North.

William Tunmer is Professor of Educational Psychology, and holds a PhDin Experimental Psychology from the University of Texas at Austin. His research interests include language-related factors in reading disability and the development of young children's literacy skills.

Jane Prochnow is a Senior Lecturer, and her research interests include cognitive-motivational factors in beginning literacy achievement and causal factors associated with school behaviour difficulties.

James Chapman is Professor of Educational Psychology, with research interests including cognitive-motivational factors in beginning literacy achievement and in learning disabilities, and the development and assessment of achievement-related self-perceptions. 